\title{
NUMERICAL INVESTIGATIONS TO THE EFFECTS OF THE PROPOSED DAMS ON THE BLUE NILE BASIN DISCHARGE
}

\author{
Ghorab, E1, Helal Y. Esam2, Mahgoub, S 3, \\ Sobeih M.F.4and Shalash A5 \\ 1Assoc. Prof., Hydraulics Research Institute, National Water Research Centre, Egypt \\ 2Assistant Prof., Faculty of Engineering, Minoufiya University, Egypt \\ 3Assoc. Prof., Hydraulics Research Institute, National Water Research Centre, Egypt \\ 4Professor of Hydraulics, Faculty of Engineering, Minoufiya University, Egypt \\ 5Assistant Researcher, Water Resources Research Institute, National Water Research Centre, Egypt
}

\begin{abstract}
This investigation was initiated due to the importance of using decision support tools for water resources planning so as management and due to the significance of the Blue Nile together with the impacts of population growth so as economic expansion. RIBASIM model was used to study the effect of some proposed control structures on the Blue Nile basin. The model was set up using readily available input data which includes river basin network schematization, hydrologic data and model data characterizing each node so as the links. The model was calibrated using annual volume-discharge of the Blue Nile basin. The yearly incomes were used to quantify the outflow from the Blue Nile. The performance of the calibrated model was assessed with different techniques.
\end{abstract}

A reasonable agreement was observed in the annual water balances and hydrographs' shape. Confident with the calibration process results, the model was used for further analysis of the whole Nile basin and elemental sub-basins related to future trends of the main river flow and its hydrological components. Different scenarios were designed and the expected effects of constructing the proposed dams on the yearly income of the Blue Nile were calculated.

It was found that, the yearly income would decrease by $2.17,2.42,2.26,1.99,10.24,9.05$ or $10.38 \%$ if $1,2,3,4,5$, 6or 7 dams, respectively, were constructed. These results were based on a randomly selected representative year to show the effect of the proposed dams on the yearly income of the Blue Nile.

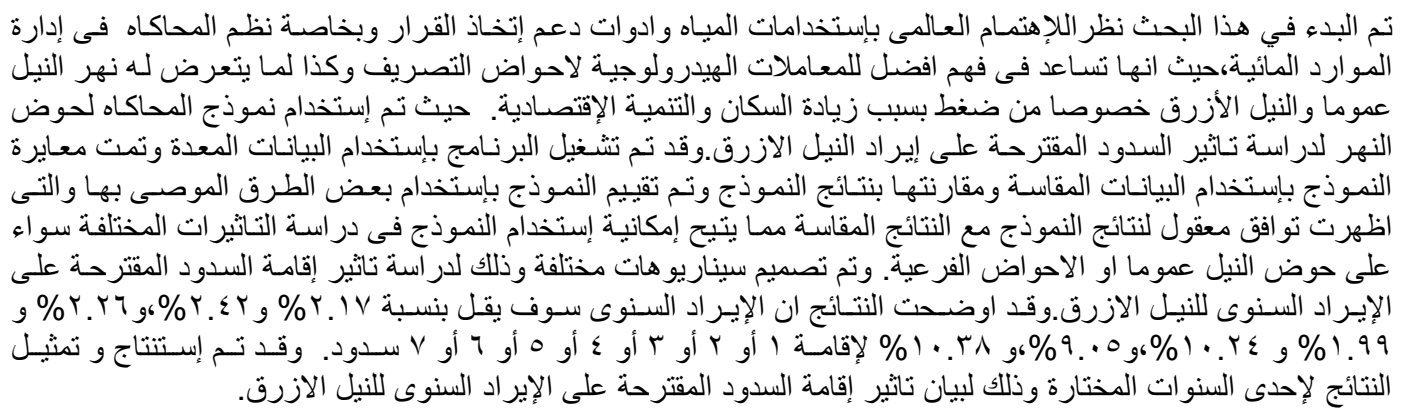

Keywords: Dams, Blue Nile Basin, RIBASIM Simulation Model

Engineering Research Journal, Vol. 36, No. 1, January 2013, PP: 69-77 


\section{INTROUDUCTION}

The Blue Nile originates from Tana Lake in Ethiopia. It provides an average of $58 \%$ of the Nile's waters in Egypt. It contributes $17 \%$ of the Nile's waters in the low-water season and $68 \%$ during the high-water season. In contrast, the White Nile provides only $10 \%$ of the Nile's waters during the high water season but contributes more than $80 \%$ during the low water period. The Blue Nile has a steeper gradient and flows more swiftly than the White Nile, which joins at Khartoum. Unlike the White Nile, the Blue Nile carries a considerable amount of sediment; for several kilometers North of Khartoum,

\section{LITERATURE REVIEW}

Literature was reviewed in the field of simulation modeling and (DSS). From the reviewed literature, it was clear that several researchers dealt with the subject worldwide;

- USBR (1964) discussed the proposed dams of the Blue Nile.

- Fitz, H.C. (2002) reported the calibration and checking model performance of models.

- Guariso, G., (1987) discussed the importance of the Ethiopian water to the development of Egypt.

- $\quad$ Paul J Block. (2007), Shahin, M. (1985), Conway (2000) reported the hydrology and climate of the Nile Basin.

- Ribasim (2004) is considered to be the technical reference manual of the model used in this paper.

- S. M. Ramadan (2011) cited that Planning Sector, Ministry of Water Resources and Irrigation, Egypt, used the model to assess alternatives for peter management of Lake Nasser, to enhance the modeling facilities of the Nile Forecasting Centre, and to initiate benefit from co-operation within the Nile basin

- Thomson Gale, (2006), World Energy Council. (2001), Arsano and Tamrat (2005) cited the alternative energy and the survey of energy and water resources for irrigation in Ethiopia.

\section{PROBLEM DEFINITION}

Ethiopia possesses abundant water resources and hydropower potential, yet only three percent of this potential has been developed, World Energy Council (2001). Likewise, less than $5 \%$ of irrigable land in the Blue Nile basin has been developed for food production (Arsano and Tamrat 2005). The Ethiopian government is therefore pursuing plans and programs to develop hydropower and irrigation through the construction of seven proposed dams, in an effort to reduce poverty and create a social change.

\section{METHODOLOGY}

Numerous hydrologic models have been developed to assess hydropower and agricultural irrigation potential within Ethiopia and the Nile River basin,Guariso and Whittington (1987), Levy and Baecher (1999), Geogakakos (2004) and Whittington et al. 2005). These models can support the identification of suitable hydropower and irrigation projects, with implications to hydrology and economics of the entire basin. This paper utilized the RIBASIM model for hydropower and irrigation analysis for these proposed dams. Through the use of the model, the effect of the proposed dams would be studied. The model results for randomly selected year were compared and presented to show the effect of the proposed dams on the yearly income of the Blue Nile.

\section{BLUE NILE BASIN}

The Blue Nile headwaters emanate at the outlet of Tana Lake in the Ethiopian highlands, as presented in Figure (1). It is joined by many important tributaries, draining the central and southwestern Ethiopian highlands, becoming a mighty river long before it reaches the lowlands and crosses into Sudan. It stretches nearly 850 kilometers between Tana Lake and the Sudan-Ethiopian border, with a fall of 1300 meters; the grades are steeper in the plateau region, and flatter along the low lands. From approximately 30 kilometers downstream of Tana Lake and into Sudan, the river flows through deep rock-cut channels.

\section{5.a. Blue Nile Hydrology}

Very few stream gauges exist along the Blue Nile River within Ethiopia with limited records, and are not publicly available. Upon leaving Lake Tana, the next station location of substantial length is at Roseires in Sudan. Stations with shorter records, at Kessie, downstream of Tana Lake, and El Diem, at the SudanEthiopian border, exist, but provide only a few years of monthly flows.

\section{5.b. Climate}

The climate in the Blue Nile River basin varies greatly between its inception in the highlands of Ethiopia and its confluence with the White Nile River. Tana Lake is 1830 meters above sea level with an annual average precipitation of nearly $1000 \mathrm{~mm}$ and evaporation rates of $1150 \mathrm{~mm}$ per year. Most of the highlands of Ethiopia, at elevations between 1500 and 3000 meters, are wet, lush and green. They have daily mean temperatures that fluctuate between $15^{\circ}$ and $18^{\circ}$ Celsius, Paul J. Block (2007). As the Blue Nile drops into the lowlands and into southern Sudan, rainfall decreases and evaporation increases, resulting in a significant net loss. Temperatures also increase in variability, and reach substantially higher levels than Tana Lake. The Sennar region, located in the southeastern part of Sudan, experiences evaporation rates of $2500 \mathrm{~mm}$ per year, yet, it only receives 500 $\mathrm{mm}$ of rain annually; mean daily temperatures 
approach $30^{\circ}$ Celsius,Shahin (1985), Sutcliffe and Parks (1999).

Monthly precipitation records indicated a summer monsoon season, with highest totals in June till September. During this season, it rains $90 \%$ of the total precipitation, near Sennar, Sudan, while in the Ethiopian highlands, approximately $75 \%$ of the annual precipitation falls during the monsoon season. August is typically the peak month, with 2 to 3 hours of average daily sunshine and humidity levels are close to $85 \%$ in the Ethiopian highlands, Shahin (1985) and Conway (2000).

Due to its equatorial positioning, the Nile River is ripe for evaporation in its channels and reservoirs, and evapotranspiration through irrigation practices. It is estimated that tens of billions of cubic meters are lost annually from these processes.

\section{PROPOSED DAMS}

In 1964, the (USBR), upon invitation by the Ethiopian government, performed a thorough investigation to study the hydrology of the upper Blue Nile basin. Included in the study was an optimistic list of potential projects within Ethiopia, including preliminary designs of four dams for irrigation and hydroelectric power along the Blue Nile River, Figure (1). The four major hydroelectric dams along the Blue Nile are The Karadobi Dam and reservoir would be located just upstream of the Guder River confluence, Approximately $385 \mathrm{~km}$ downstream of Tana Lake, and would be responsible for controlling a draining area of nearly 60,300 kilometers squared. The Mabil Dam would be $145 \mathrm{~km}$ further downstream, $25 \mathrm{~km}$ downstream of the confluence with the Birr River. The Mendaia and Border Dams would be constructed about $175 \mathrm{~km}$ and $21 \mathrm{~km}$ upstream of the Sudanese-Ethiopian border, respectively. Another three proposed dams (Beles dam at Beles River near Tana Lake, Angar Dam up stream of Mendaia Dam, and Dinder Dam). With the proposal of the three additional dams the total number would be seven dams.

Preliminary plans suggested generally dam construction order from upstream to downstream. This plan attempts to capture flows leaving the country earlier in the construction timeline to take advantage of hydroelectric potential. The Model and evaluations in this paper incorporate the construction order from upstream to downstream. Operating in tandem, these proposed dams would be capable of providing electricity to millions of homes. The total installed capacity at design head would be 5570 megawatts of power, about 2.5 times the potential of the Aswan High Dam in Egypt, and this would be an impressive upgrade over the existing $529 \mathrm{MW}$ of hydroelectric power within Ethiopia as of 2001, (Thomson Gale (2006).

\section{RIVER BASIN SIMULATION MODEL}

RIBASIM model was developed by WL DELFT HYDRAULICS. It is a generic model package for simulation of the behavior of river basins during varying hydrologic conditions. The model is a comprehensive and flexible tool to link the hydrologic inputs of water at various locations to the various water-using activities in the basin, infrastructure and operational management.

Input for RIBASIM model covers the following: River basin network schematization, Model data characterizing each node and link, Water allocation rules and operation rules, Hydrologic data, open water evaporation, rainfall, general district water demand and discharges, water district runoff.

Simulation results can be processed with a number of standard post-processors into graphs, spreadsheets, maps, and tables. The results can be further processed with spreadsheet software like MS Excel or directly included in reports produced e.g. with MS Word. Tables range from summaries of the main results to user-defined tables with detailed results per time step for specific variables per node or link.

\subsection{Model Schematization}

Basin planning exercise requires a comprehensive inventory and thorough understanding of all water related systems in the basin. To perform river basin simulations with the model, a model schematization of the study area was prepared in the form of a network, consisting of nodes connected by links, Figure (1). Such a network represents all the features of the basin that play a role in its water balance. Supplies and the water user activities were connected to the network as nodes. The transport of water in the network takes place in links. The transport of water was controlled by the operation rules as specified by the user. The time aspect was brought in by the time series of discharges (inflows), rainfall etc. and also in the form of time series for the water demands.

\subsection{Simulation}

Simulations were made to analyze a specific (present or future) condition over long series of historical years to cover sequences of dry and wet periods. The simulation proceeds in time steps, of typically one month, half a month or 10 days. In essence, the model is a water balance model. Within each time step a water balance calculation was made. Simulation of the water balance of the region/basin forms the basis for such analysis. It provides the means to prepare such balance with sufficient detail, and with facilities to vary the simulated configuration and to process results. 


\subsection{Model Calibration}

The main purpose of calibration was to see how the built model predicts the reality. That means to minimize the difference between model and reality; therefore statistical equations were developed for regression and model fitting techniques to measure how the simulated outputs fit the observed data. In most watershed modeling projects, model output was compared to corresponding measured data with the assumption that all error variance was contained within the predicted values and that observed values were error free.

\subsection{Checking Model Performance}

A number of statistical measures as suggested by Fitz et al. (2002) were used to evaluate model results, including model bias, root mean square error (RMSE), Pearson product-moment correlation coefficient $\left(\mathrm{R}^{2}\right)$, and the Nash-Sutcliffe coefficient. The three criteria were also, recommended by the ASCE (American Society of Civil Engineers) Task Committee on Definition of Criteria for Evaluation of Watershed Models (1993).

Brief overviews of these statistical measures are provided below;

\section{4.a. Nash-Sutcliffe coefficient}

Nash-Sutcliffe coefficient measures the efficiency of the model by relating the goodnessof-fit of the model to the variance of the measured data,

$$
N . S=1-\frac{\sum_{i=1}^{n}\left(Q_{i}-Q_{i}^{\prime}\right)^{2}}{\sum_{i=1}^{n}\left(Q_{i}-\mu\right)^{2}}
$$

Where, $\mathrm{Q}_{\mathrm{i}}$ is the yearly measured value, $\mathrm{Q}{ }^{{ }_{\mathrm{i}}}$ corresponds to the simulated value by RIBASIM, $\mu$ represents the measured mean value for the simulation period and $\mathrm{n}$ is the observations number for compared values.

A Nash-Sutcliffe value can vary between $-\infty$ and 1.0, with N.S = 1.0 being the optimal value. Values between 0.0 and 1.0 were generally viewed as acceptable levels of performance, whereas values $<0.0$ indicates that the mean observed value was a better predictor than the simulated value, which indicates unacceptable performance.

\section{4. b. Coefficient of Determination}

Coefficient of determination describes the proportion of the variance in measured data explained by the model. $\left(\mathrm{R}^{2}\right)$ ranges between 0 and 1 , with higher values indicating less error variance, and typically values greater than 0.5 were considered acceptable, Santhi et al. (2001) and Van Liew et al. (2003). It is defined as the goodness of fit that can be quantified by the coefficient of determination $\left(\mathrm{R}^{2}\right)$ between the observations and the final best simulation.

Coefficient of determination was calculated using the following equation:

$$
R^{2}=\frac{\left[\sum_{i}\left(Q_{m . i}-Q_{m}\right)\left(Q_{s . j}-Q_{s}\right)\right]^{2}}{\sum_{i}\left(Q_{m . i}-Q_{m}\right)^{2} \sum_{i}\left(Q_{s . i}-Q_{s}\right)^{2}}
$$

Where $\mathrm{Q}_{\mathrm{mi}}$. is the measured discharge, $\mathrm{Q}{ }_{\mathrm{si}}$. is the simulated discharge, $\mathrm{Q} m$ is the average measured discharge and $\mathrm{Q}_{\mathrm{s}}{ }_{\mathrm{s}}$ is the average simulated.

\section{4. c. Percent Bias (PBIAS)}

Percent bias (PBIAS) measures the average tendency of the simulated data to be larger or smaller than their observed counterparts. The optimal value of PBIAS is 0.0 , with low magnitude values indicating accurate model simulation. Positive values indicate model underestimation bias, and negative values indicate model overestimation bias, Gupta et al. (1999).

PBIAS is calculated using the following equation:

PBIAS

$$
=\left\{\frac{\sum_{i}^{n}\left(Q_{i}-Q_{i}^{\prime}\right)^{*}(100)}{\sum_{i=1}^{n} Q_{i}}\right\}
$$

Where $Q_{i}$ is the yearly measured value, $Q{ }^{1}{ }_{i}$ corresponds to the simulated value by RIBASIM, PBIAS is the deviation of data being evaluated, expressed as a percentage.

\section{4. d. Calibration Results and Discussions}

In order to judge the model performance in predicting the reality, the yearly discharges from the Blue Nile basin was selected. Simulated and measured annual discharges from year 1912 to year 1973 were used. The model output was compared to the corresponding measured data, Shahin (1985).

\section{4. e. Flow Calibration}

The calibration results for annual flows are given here, Figure (2). The average tendency of the simulated data to be larger or smaller than the observed was calculated by Bias to be $15.695 \%$. This means that most of the time the peak discharges were underestimated, as a positive value indicating that the model underestimation bias, This may be attributed to local rainfall storms that were not well represented by the rainfall data used in the hydrologic simulations. There was an agreement between some observed and simulated flow but in general, underestimation was dominant. However, the performance of the model in simulating yearly flow was good. It has satisfactorily 
simulated the flows with (N.S of $0.4698, \mathrm{R}^{2}$ of 0.75337 and positive Percent bias).

\section{DESIGN OF SCENARIOS}

An endless number of scenarios could be constructed for assessing hydropower and irrigation optimization in the Blue Nile basin, including variations in flow policies, interest rates, climatic conditions, the timing of bringing dams online, etc. To assess the model results seven scenarios were constructed and one year was chosen as a representative year. Therefore, the number of scenarios for this study was selectively pared down with the intention of adequately scoping a relevant range of possibilities that could inform policy and planning decision-making.

\section{MODEL RESULTS AND DISCUSSION}

The designed scenarios were simulated. The results were obtained and analyzed.

A base case was simulated. This case assumed that no dams were constructed. The discharge used in this simulation was $15399.08 \mathrm{~m}^{3} / \mathrm{sec}$.

In this paper, it is proposed to present a scenario analysis approach to study the effect of future development of the Blue Nile River basin water system under different scenarios of these proposed control structures:-

The first scenario: one dam (Dinder dam) was simulated. Although the Dinder dam was an irrigation dam; it has a limited effect on the monthly flow. The Model indicated an annual reduction of stream flow at the outlet of the Blue Nile River basin of $2.172 \%$. If the dam was operated alone it will not be able to control the discharges at the outlet of the Blue Nile River basin. There will be no water released downstream in March and April. The maximum water release will be in August to minimize the amount of sediment upstream the dam, Figure (3).

Second scenario: This scenario simulated the addition of another dam to operation (Beles dam). This dam is a hydro power - irrigation dam. a limited effect on the monthly flow was detected. The Model indicated a mean annual reduction of $2.422 \%$. The two dams (Dinder and Beles) were still not able to control the seasonality of the Blue Nile River. There would be no water released downstream in March April and May. The maximum release will be in August, Figure (4).

Third scenario: this scenario simulated the addition of a third dam (Menddaia), after the construction of the proposed three dams (Dinder, Beles and Menddaia). The operation of the three proposed dams has a limited effect on the monthly flow of the Blue Nile River, with annual reduction of $2.265 \%$. The seasonality of the basin was still exist, Figure (5).

Forth scenario: This scenario simulated the case when the Mabil dam was added to operation, the four proposed dams, (Dinder, Beles, Menddaia and Mabil). The effect was still limited on the monthly flow. The Model indicated a mean annual reduction of $1.989 \%$, Figure (6).

Fifth scenario: This scenario simulated the case when the newly proposed dam, (Karadobi) was a hydropower dam, and would be responsible for controlling a draining area of nearly 60,300 kilometers squared, Kendie, Daniel (1999). When The Karadobi Dam operates alone, the flow at the outlet of the Blue Nile River would be decreased by $9.584 \%$. When the five proposed dams, (Dinder, Beles, Menddaia, Mabil and Karadobi) are in operation the flow at the outlet of the basin is going to have a concrete effect.

The Model indicated a mean annual reduction of stream flow at the outlet of the basin of $10.238 \%$. With the operation of the fifth dam the Blue Nile River was not seasonal any more, Figure (7). The high evaporation rate and other losses such as seepage is the direct cause of the annual flow reduction.

Sixth scenario: This scenario simulated the case when Angar was an irrigation dam. When the Angar dam operates alone the Model indicated a mean annual increase of stream flow at the outlet of the basin by $1.359 \%$. When the six proposed dams, (Dinder, Beles, Menddaia, Mabil, Karadobi and Angar) were in operation the monthly flow at the outlet of the Blue Nile River is going to have a slight improvement more than the previous case. The Model indicated a mean annual reduction of $9.052 \%$. The Blue Nile River was not seasonal, Figure (8).

Seventh scenario: the Border was only a hydropower dam. When the Border dam operates alone the Model indicated a mean annual reduction of $0.216 \%$. When the seven proposed dams, (Dinder, Beles, Menddaia, Mabil, Karadobi,Angar and Border) were in operation, the model indicated a mean annual reduction of stream flow at the outlet of the Blue Nile River basin of $10.382 \%$ and the River was not seasonal, Figure (9).

\section{CONCLUSIONS}

The Blue Nile, which originates at Tana Lake in Ethiopia, contributes a large portion of the total flow of the Nile as it provides an average of $58 \%$ of the Nile's waters in Egypt. The Blue Nile is on great pressure due to the impacts of population growth and economic expansion. River basin models are interactive programs that utilize analytical methods, such as simulation and optimization algorithms, to help decision-makers formulate water resources alternatives, analyze their impacts, and interpret and select appropriate options for implementation. 
Models are used to simulate water resource system behavior based on a set of rules governing water allocations and infrastructure operation and can predict the behavior of the basin under divergent conditions or management scenarios.

In this paper, the model was used to study the effect of some proposed control structures at the Blue Nile basin. The analyses conducted quantify some of the possible impacts arising from future development of the water resources of the Blue Nile basin.

The simulation model was run for the complete year of 1973, this being the year representative for a relatively low flow year.

Calibration through the comparison of observed and simulated annualized discharge at the outlet of the Blue Nile for the period from 1912 to 1973, indicated the model performance in simulating yearly flow is good; it has satisfactorily simulated the flows with (N.S of 0.469857 andR $^{2}$ of 0.75337 ).

The modeling results indicated that the annual water income would be affected by different percentages at each scenario as follow:

- When constructing one dam; the yearly income will decrease by $2.17 \%$.

- Two dams; the yearly income will decrease by $2.42 \%$.

- Three dams; the yearly income will decrease by $2.26 \%$.

- Four dams; the yearly income will decrease by $1.99 \%$.

- Five dams; the yearly income will decrease by $10.24 \%$.

- Six dams; the yearly income will decrease by $9.05 \%$.

- Finally, when constructing seven dams; the yearly income will decrease by $10.382 \%$ ).

\section{RECOMMENDATIONS}

Although the model results gave an idea about the effect of dams construction on the Blue Nile income, but the effects of climate change, sedimentation, public health, current and proposed relocated communities, the prevalence of livestock, and people's willingness to adapt to proposed behavioral changes, which all need a comprehensive studies, as all these items are crucial in formulating strategies to mitigate negative effects.
Also a comprehensive study of the filling stage of each dam had to be done with all the riparian countries.

\section{ACKNOWLEDGMENTS}

This work is part of $\mathrm{PhD}$. Thesis of the fifth author and supervised by the other authors. The authors are gratefully to the Water Resources Research Institute, WRRI; National Water Research Center, Egypt.

\section{REFERENCES}

[1] Bureau of Reclamation, US Department of Interior. (1964). Land and water resources of Blue Nile Basin: Ethiopia. Main Report and Appendices I-V. Washington, D.C.: Government Printing Office.

[2] Fitz, H.C., N. Wang, J. Godin, F.H. Sklar, B. Trimble, and K. Rutchey (2002). Calibration Performance of Water Quality and Hydrology.

[3] Guariso, G., and D. Whittington.(1987), Implications of Ethiopian water development for Egypt and Sudan. International Journal of Water Resources Development 3(2): 105-114.

[4] Paul J Block. (2007), Integrated Management of the Blue Nile Basin in Ethiopia: Hydropower and Irrigation Modeling.

[5] Ribasim Version 6.32 Technical Reference manual, July (2004).

[6] -Shahin, M. (1985), Hydrology of the Nile Basin, Amsterdam: Elsevier.

[7] S. M. Ramadan, A. M. Negm, and T. M. Owais (2011), Effect Of New Upper Nile Projects On The Integrated Management Of The Basin: Review And Methodology, Fifteenth International Water Technology Conference, IWTC-15 2011, Alexandria, Egypt

[8] Sutcliffe, J. and Y. Parks. (1999), The hydrology of the Nile. Wallingford, Oxfordshire, UK: IAHS Press.

[9] Thomson Gale, (2006), Alternative Energy [3 Vols] - N. Schlager, J. Weisblatt

[10] World Energy Council. (2001), Survey of energy resources, (2001). London, UK. 


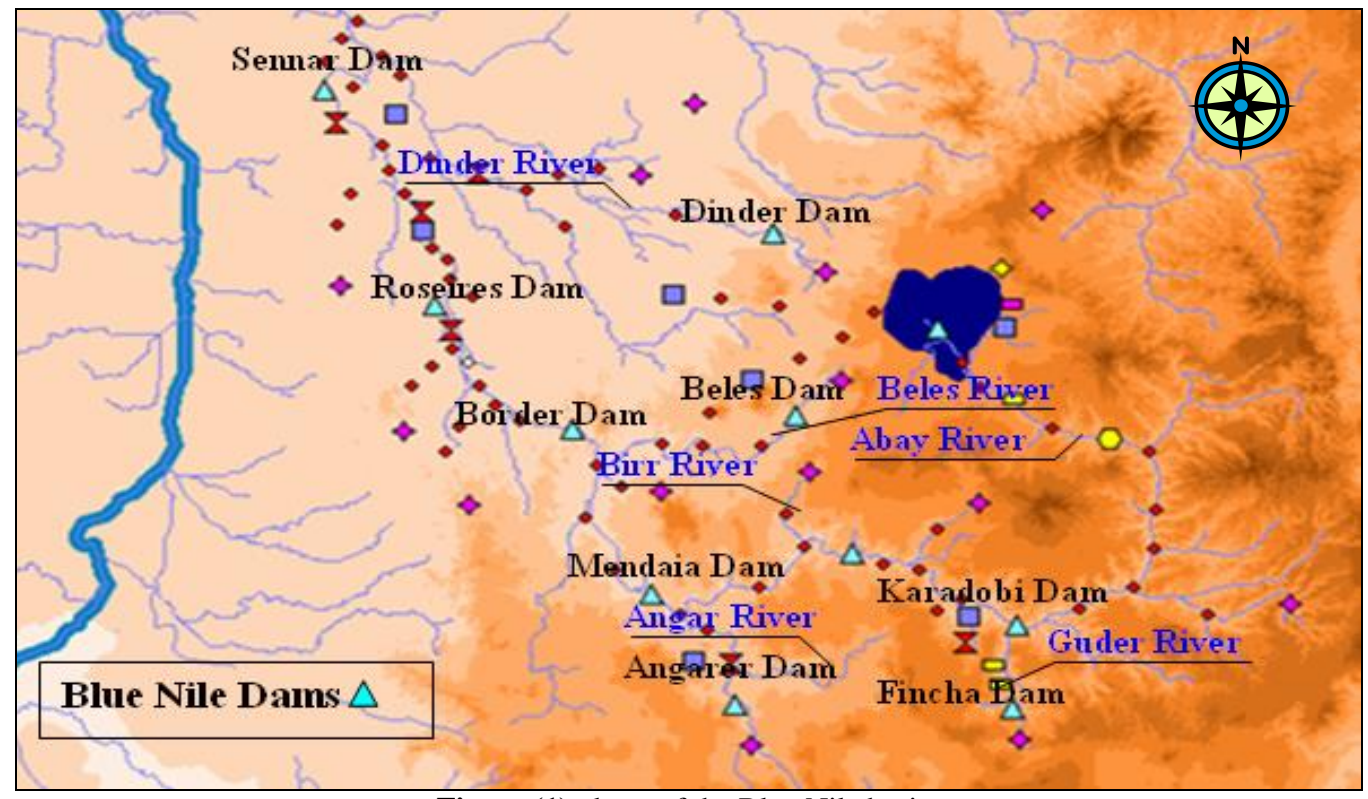

Figure (1) dams of the Blue Nile basin.

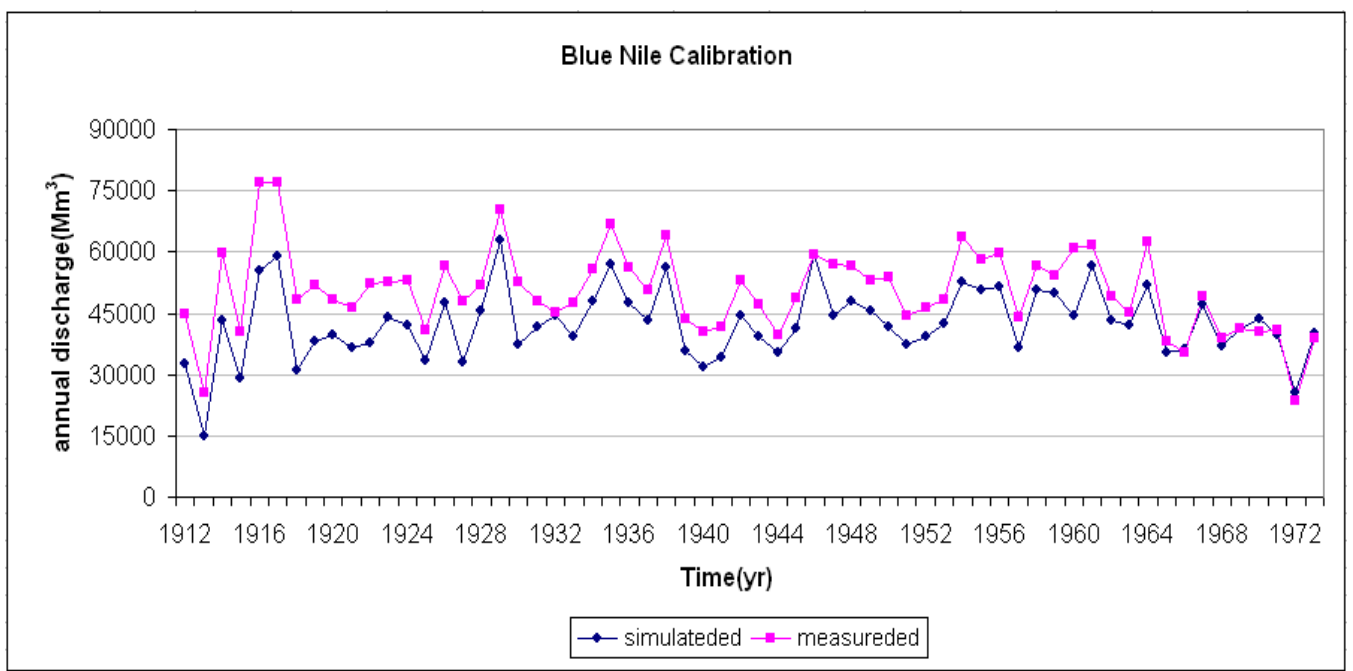

Figure (2) Comparison between Measured and Simulated results.

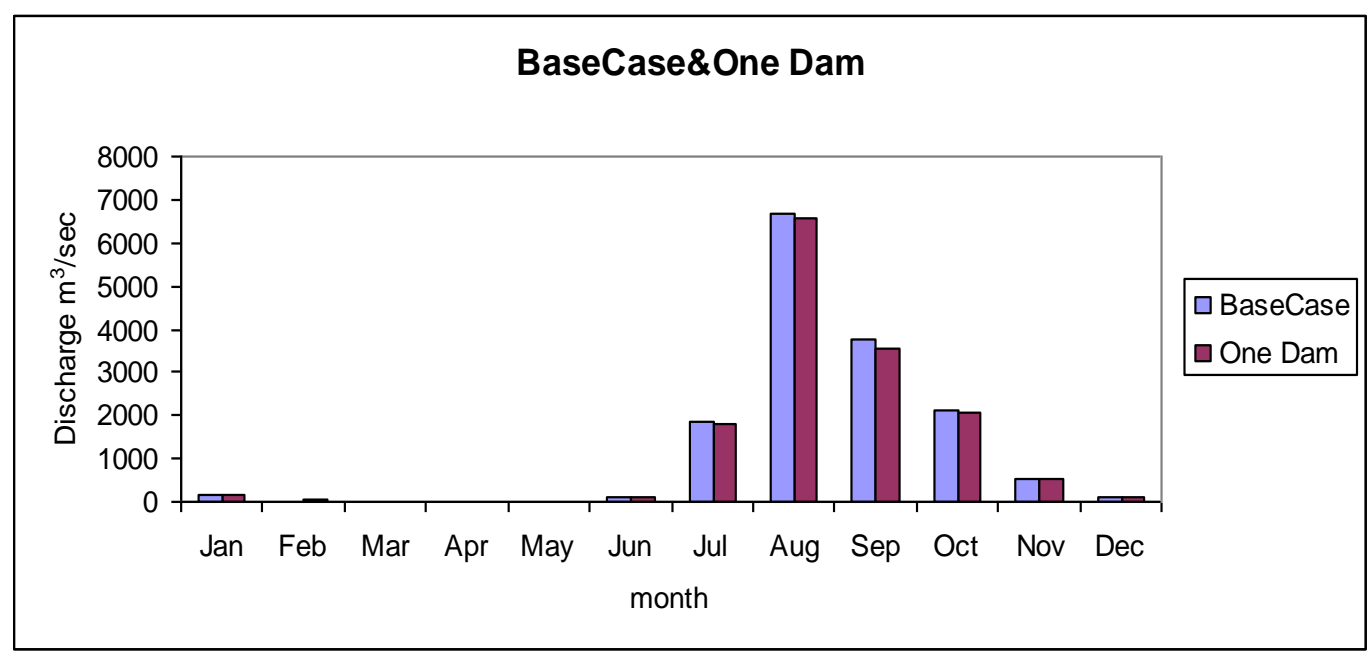

Figure (3) Comparison between Base Case and Case of one dam (Dinder Dam). 


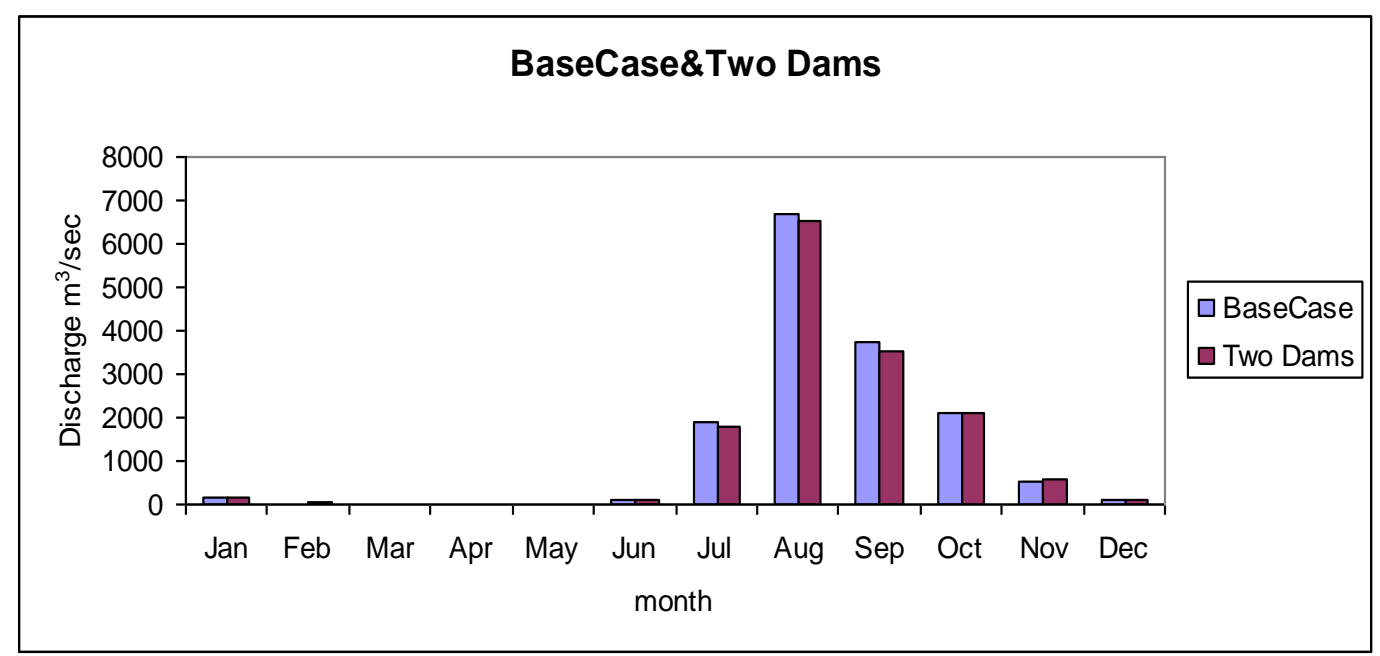

Figure (4) Comparison between Base Case and Case of two dams (Dinder \&Beles Dams).

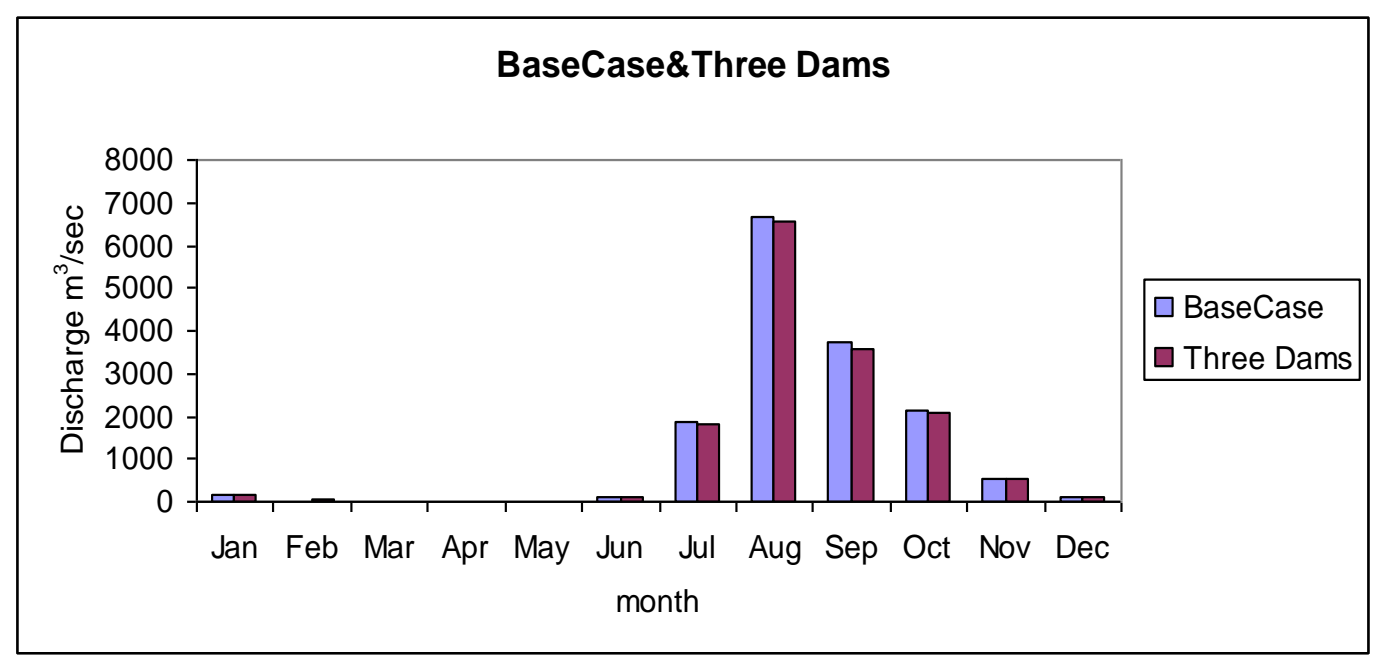

Figure (5) Comparison between Base Case and Case of three dams (Dinder, Beles \& Mendaia Dams).

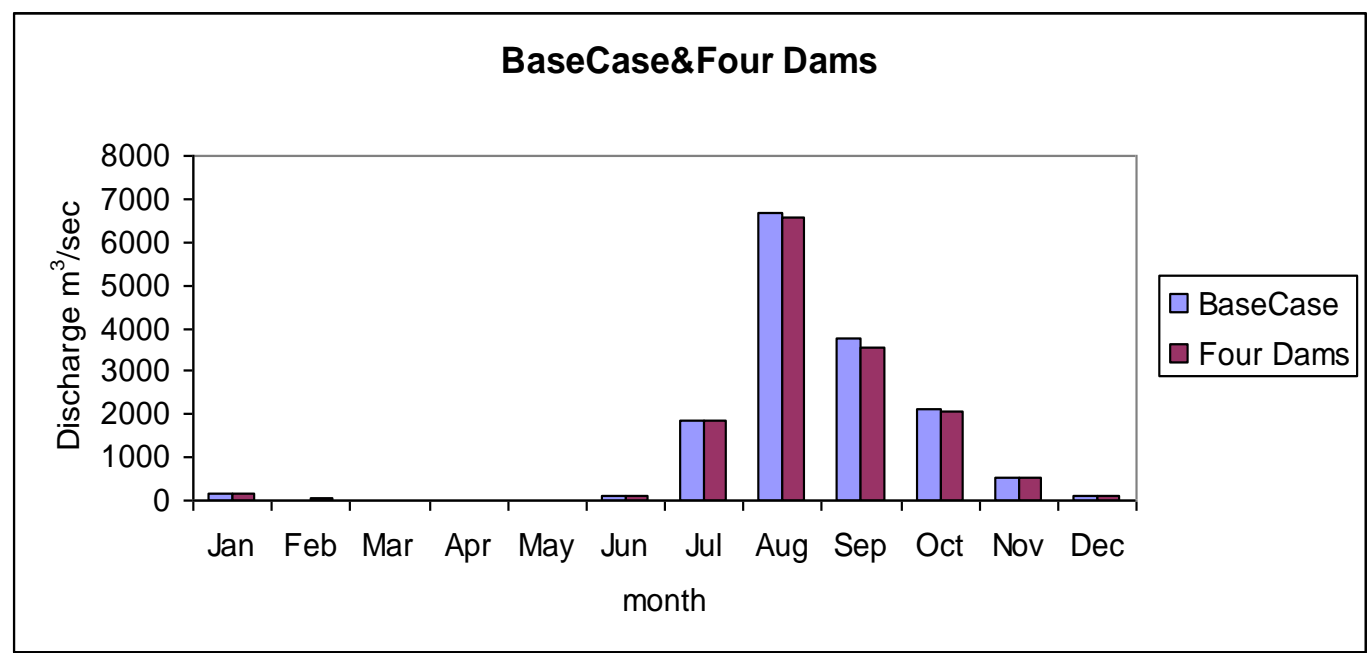

Figure (6) Comparison between Base Case and Case of four dams (Dinder, Beles, Mendaia \& Mabil Dams) 


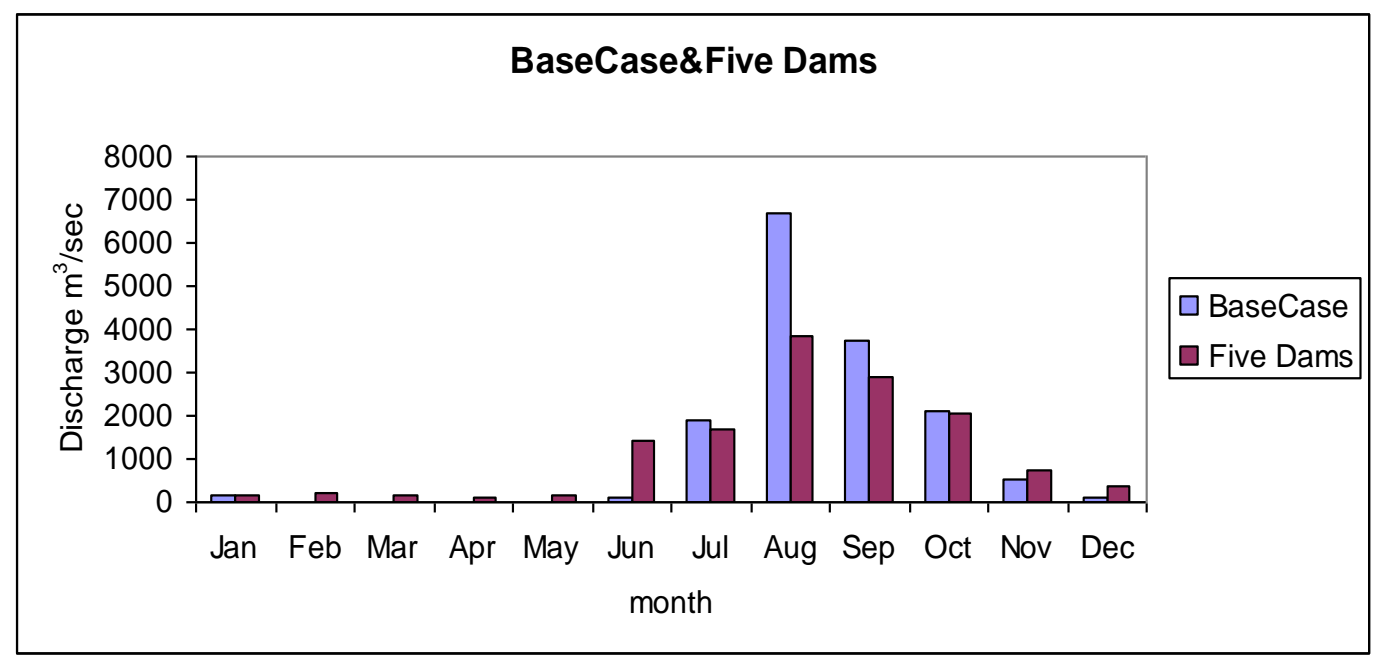

Figure (7) Comparison between Base Case and five dams (Dinder, Beles, Mendaia, Mabil \&Karadobi Dams)

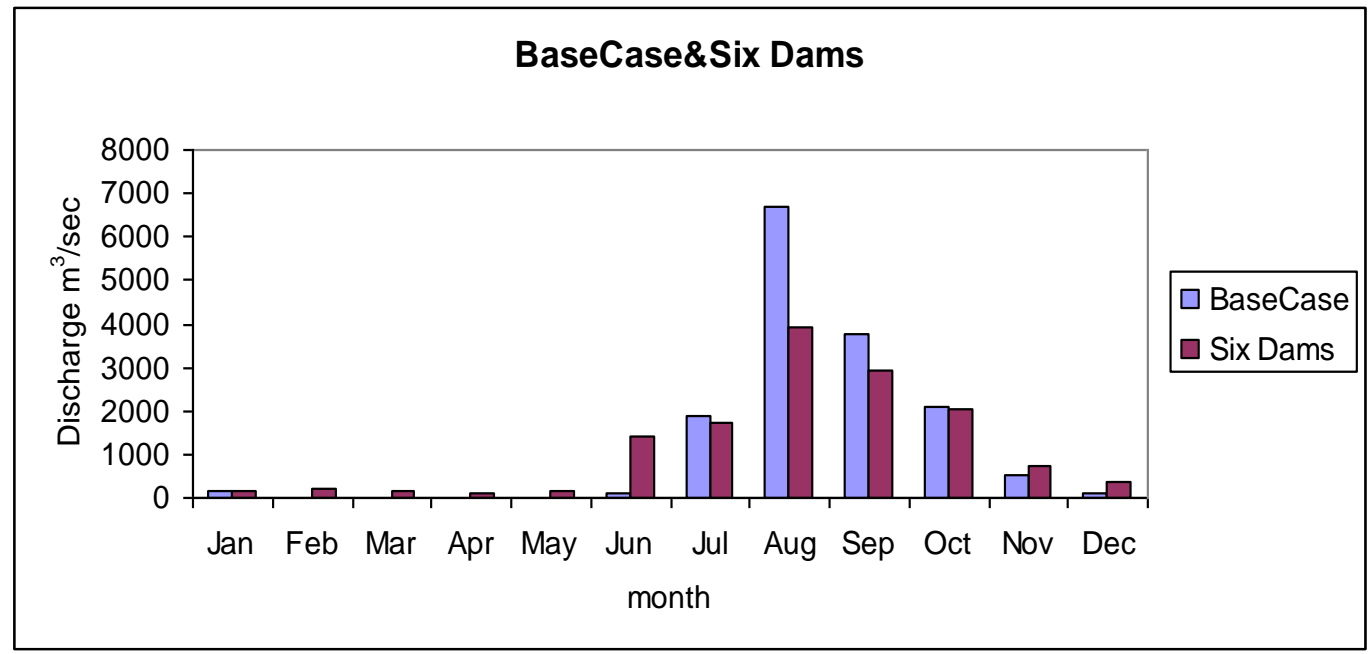

Figure (8) Comparison between Base Case and six dams

(Dinder, Beles, Mendaia, Mabil, Karadobi\& Angar Dams)

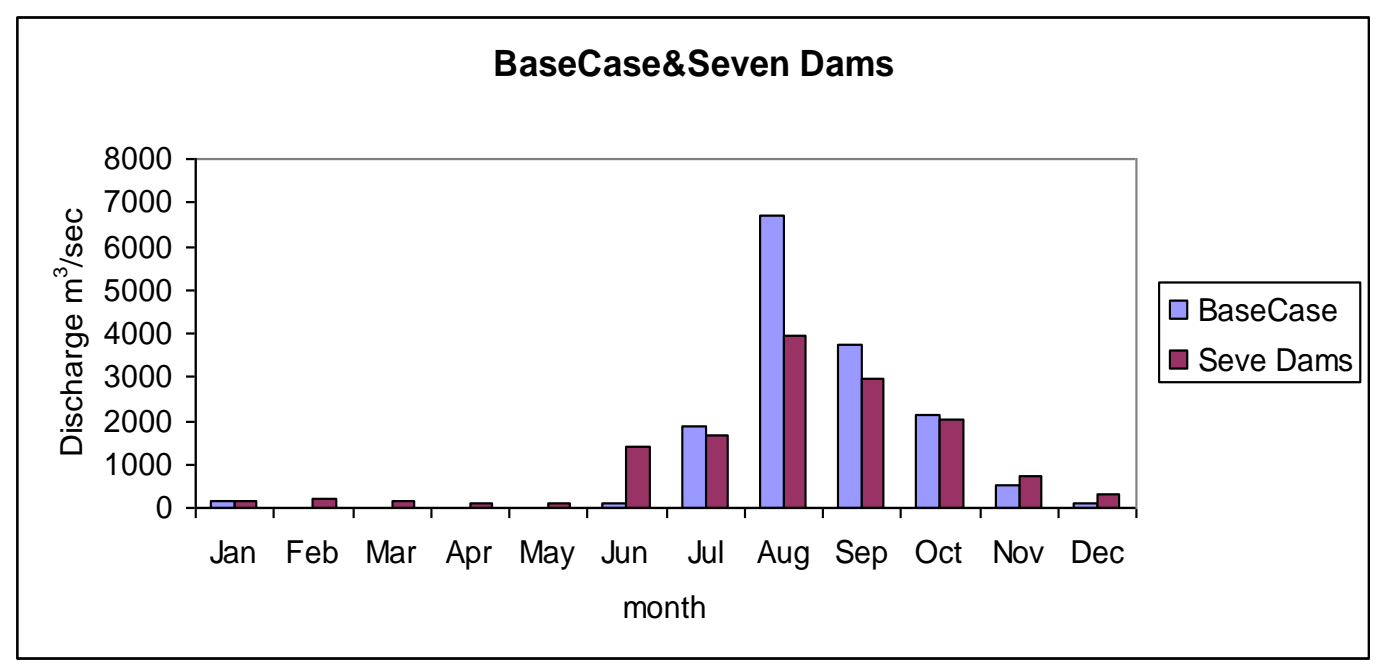

Figure (9) Comparison between Base Case and Case of seven dams

(Dinder, Beles, Mendaia, Mabil, Karadobi Angar, \&Border Dams) 